\title{
ARTIGO
}

\section{A importância da cultura crítica na construção de um novo Estado}

\author{
Marília Gabriella Borges Machado ${ }^{1}$
}

Como citar este artigo: MACHADO, Marília Gabriella Borges. A importância da cultura crítica na construção de um novo Estado. Revista de Ciências do Estado. Belo Horizonte: v. 5, n. 1, e13164. ISSN: 2525-8036.

Resumo: Trata-se de um trabalho teórico que empreende uma abordagem histórica. $\mathrm{O}$ objetivo central deste estudo é o de seguir a apreensão teórica / prática de Antonio Gramsci relativa à experiência dos Conselhos de Fábrica como o fundamento de uma nova democracia e de um novo Estado a partir do vínculo entre cultura e socialismo. A cultura é definida como esfera, pensamento, estrutura de atividades e construção de consciência realizada por camadas intelectuais orgânicas à classe operária, ou seja, pelas massas que exercem funções organizativas na produção e no modo cultural. Portanto, este trabalho pretende realizar uma análise da função da cultura relacionada à experiência dos Conselhos de Fábrica, em Turim (1919-1920), de maneira que a questão organizativa fica em evidência na categoria de cultura. As fontes utilizadas são os textos de Antonio Gramsci e importantes autores que discutem a teoria gramsciana, a fim de obter compreensão do cenário político e teórico que Gramsci se encontrava.

Palavras-chave: cultura; Gramsci; socialismo.

Recebido em 13.06.2019

Aprovado em 01.03.2020

Publicado em 26.03.2020

\section{O DESENVOLVIMENTO DA CATEGORIA CULTURA NA OBRA}

\section{GRAMSCIANA}

A categoria cultura é essencial para compreender a obra de Antonio Gramsci. Pode ser observada desde os textos da juventude, a partir de 1911, até os textos escritos no cárcere, a partir de 1932. Cultura é uma categoria bastante ampla e capaz de denotar diversos significados desde que analisados em seu desenvolvimento. Uma categoria de grande mobilidade que, em primeiro momento, é compreendida como autodisciplina, algo que o

\footnotetext{
1 Mestranda em Ciências Sociais pela UNESP/FFC, com financiamento CAPES. E-mail: gabriella.borgesmachado@hotmail.com. Lattes: http://lattes.cnpq.br/8581917241957634.
} 
proletariado e os revolucionários deveriam exercer coletivamente para transformar o meio que vivem. Posteriormente, no cárcere, a cultura é compreendida como expressão da sociedade, como noção de senso comum. A complexidade da categoria está relacionada com o termo "expressão", já que para Gramsci "toda expressão possui uma língua historicamente determinada.". (GRAMSCI, 1977, Q. 9, 132, 1.193, 197). (BARATTA apud GRAMSCI, 2017, p.172). Dessa forma, Gramsci compreende a diferença de locais, regiões, nacionalidades e continentes, tanto por conta das culturas, como das linguagens.

Cultura passa a ter o significado de unificação cultural do gênero humano. Por um lado, há a proposta de uma nova concepção de mundo relacionada com o desenvolvimento humano e o trabalho exercido pelo proletariado. Por outro lado, cultura é vista como uma religião laica -- a partir de uma cultura crítica e formação humanista--, que, para Gramsci, é uma filosofia que se transforma em cultura e que gera ética, um novo modo de viver e um comportamento cívico que não é possível de desenvolver no capitalismo.

Nos Cadernos do Cárcere é possível conceber uma função da gênese e da totalidade dos escritos pré-carcerários com aquisições do nexo cultura-hegemonia. A cultura é definida como mundo, esfera, campo, pensamento e estrutura de atividades realizadas por camadas intelectuais, ou seja, pelas massas que exercem funções organizativas - o operário qualificado - na produção e no modo cultural. Dessa maneira, a organização do proletariado é o que diferencia a função dos intelectuais de outras funções sociais e profissionais, pois para Gramsci a cultura interessa como questão política, questão prática articulada e estruturada que organiza a vida humana e que seja organizadora da sociedade.

Tanto podemos notar que o autor considera o americanismo em contraposição a cultura do fascismo, do espírito de gladiador. Para tanto, é de grande necessidade criar uma nova cultura, uma cultura sobre uma nova base social. Gramsci é favorável à criação de uma cultura crítica que seja capaz de determinar a superação tradicional entre a cultura moderna e a cultura popular, para que seja constituída a forma moderna do laicismo tradicional para um novo Estado que é a "expressão política de uma "nova sociedade": são esses os determinantes propriamente culturais da luta hegemônica.”. (BARATTA, 2017, p. 172).

O pensador coletivo deveria realizar uma luta cultural para transformar a mentalidade popular com a necessidade de um trabalho que envolva todos os homens, num movimento cultural, para um novo humanismo em nível internacional. A concepção de Gramsci sobre a tese da tradutibilidade, nesse sentido, está relacionada à possibilidade de traduzir a linguagem e a cultura. A expressão de "civilizações semelhantes que são diferentes" trata-se de uma tradutibilidade internacional e interdisciplinar que estabelece uma relação entre o pensamento 
e a ação, entre teoria e prática, que tem como fundamento o modelo dos Soviets. "A tradutibilidade se torna assim veículo da determinação da filosofia da práxis, como o volante de uma "nova cultura".”. (BARATTA, 2017, p.173). Portanto, a filosofia da práxis está em consonância com a possibilidade de realizar uma ação criativa e de criar um novo Estado de cunho popular.

Nos anos de juventude, com a chegada de Gramsci em Turim (1911), é por volta de 1913 que conhece o movimento operário e se filia ao Partido Socialista Italiano (PSI). A partir de então, tece inúmeras críticas ao positivismo e as ações reformistas do Partido. Nos primeiros anos em Turim, desenvolve sua teoria a partir do neo idealismo crociano, em torno de 1915 se afasta intelectualmente de Croce e suas reflexões passam a ser influenciadas por Rosa Luxemburg e Georges Sorel, caminhando cada vez mais à esquerda do Partido. Observamos que a obra de Gramsci é dialética e que há um desenvolvimento constante de suas categorias, com apogeu nos Cadernos do Cárcere. Dessa forma, o autor utiliza de Croce a questão da alta cultura e da cultura popular. No entanto, supera e transforma seu sentido e:

\footnotetext{
Estabelece de forma mais rica e penetrante a questão já sugerida da superação da separação entre alta cultura e cultura popular, e formula a perspectiva de uma "reforma intelectual e moral", a qual se torna uma maneira nova, originalíssima, de pensar a revolução (BARATTA, 2017, p.173.).
}

A questão da reforma intelectual e moral é relacionada com a função principal dos intelectuais sobre determinar e organizar a revolução cultural, sendo assim, organizar a cultura para a prática revolucionária. Dessa maneira, a revolução cultural aparece como a reforma intelectual e moral. Portanto, a necessidade de criar uma cultura laica é de suma importância para a transformação da sociedade e criação de um novo Estado. Para tanto, há a necessidade de criar uma cultura forte, uma cultura do proletariado e do campesinato, que permita as classes subalternas de se expressarem e se organizarem em torno de uma nova democracia.

Gramsci explica que a questão da alta cultura é determinada historicamente e no caso da modernidade está relacionada com o dever do intelectual mergulhar na vida prática e organizar os aspectos práticos da cultura, sendo que essa formação de alta cultura ocorre apenas no "contexto de democratização do saber e de uma consequente expansão da base intelectual de uma sociedade" (ORLANDI, 2017, p. 35). Dessa forma, o momento de criação de uma nova cultura está relacionado com a possibilidade de hegemonia dos subalternos, ou seja, com a questão da formação de um novo Estado e de uma democracia operária. 


\section{A CULTURA E A POLÍTICA ITALIANA}

Gramsci observa que há uma relação entre a cultura e o intelectualismo, mas não concorda com o posicionamento de intelectuais distantes da classe trabalhadora e que não dialogam com as massas, que não são organicamente ligados a ela. O jovem sardo compreende que a cultura é uma maneira do sujeito conhecer a si mesmo para se reconhecer de igual natureza aos outros, é uma forma de pensar coletivamente e criticamente. Este é o cerne da relação de cultura com o socialismo. Vejamos que o autor diferencia a cultura do saber enciclopédico e analisa a necessidade de deixar de entender a cultura como tal, pois essa forma de cultura é prejudicial para a classe trabalhadora, pois:

A cultura é algo bem diverso. É organização, disciplina do próprio eu interior, apropriação da própria personalidade, conquista de consciência superior: e é graças a isso que alguém consegue compreender seu próprio valor histórico, sua própria função na vida, seus próprios direitos e seus próprios deveres (GRAMSCI, 2004a, p.58).

É possível compreender que o desenvolvimento da consciência operária está, nesse momento, conectado com o tema da cultura - cultura entendida como crítica marxista. $\mathrm{O}$ homem só adquire consciência de seu próprio valor aos poucos e por meio da reflexão crítica; primeiro de algumas pessoas e depois de toda uma classe "sobre as razões de certos fatos e sobre os meios para convertê-los, de ocasião de vassalagem, em bandeira de rebelião e de reconstrução social.”. (GRAMSCI, 2004a, p.58).

Segundo o autor, a Revolução Francesa foi precedida pelo Iluminismo, uma nova cultura, e ao levar em consideração o contexto histórico, uma cultura emancipadora. Gramsci (2004a, p.58) compreende que para toda transformação radical da sociedade deve existir, anteriormente e continuamente, uma formação crítica, de penetração cultural e de impregnação de ideias. Significa que não é apenas com intelectualismo, permeado por discursos com dados empíricos, que é capaz de transformar uma sociedade e desenvolver a consciência crítica na classe trabalhadora. A própria cultura crítica é uma revolução que prepara a classe trabalhadora em sua organização operária.

Em 1917, Gramsci escreve o artigo Para uma associação de cultura. O texto foi publicado em 18 de dezembro de 1917, no jornal turinês Avanti!. Nesse artigo é possível analisar a importância que o jornalista dá a questão da cultura promovida em sentido socialista, com finalidades de classe e com os limites de classe. A associação de cultura:

Deve ser uma instituição proletária, com características voltadas para uma finalidade. $\mathrm{O}$ proletariado, num certo momento de sua história, percebe que a complexidade de sua vida requer um organismo necessário às suas finalidades: e cria um organismo, com suas forças, com sua boa vontade (GRAMSCI, 2004a, p.123). 
A Associação de Cultura e os círculos socialistas deveriam preparar, em longo prazo, um local de debate e estudo sobre as questões importantes para o proletariado, não apenas no momento da atualidade, mas a fim de organizar o pensamento a partir de certo período, que possibilitará a tomada consciente de decisões em momentos imediatos. Segundo Gramsci, as classes subalternas deveriam se auto educar nos círculos de cultura, alinhados ao PSI, para que a organização operária obtivesse a capacidade de se transformar em sujeitos que produzem uma nova vida social. Por assim ser, socialismo, cultura e trabalho é um nexo muito importante na obra gramsciana e demonstram, para o autor, a possibilidade de o socialismo ser uma visão integral da vida, pois engloba junto à cultura e a auto-organização uma visão integral da vida, pois "tem uma filosofia, uma mística, uma moral. A associação seria o local próprio para a discussão desses problemas, para seu esclarecimento, para sua propagação" (GRAMSCI, 2004a, p. 124).

É com uma visão crítica, universal e coletiva dos fatos e do contexto de guerra, de formação tardia do Estado capitalista italiano e das polêmicas do Partido Socialista, que Gramsci elabora a noção de cultura relacionada à revolução socialista. Dessa forma, a categoria de cultura para Gramsci possui o significado de:

\footnotetext{
Exercício do pensamento, aquisição de idéias gerais, hábito de conectar causa e efeito. Para mim, todos já são cultos, porque todos pensam, todos conectam causas e efeitos. Mas o são empiricamente, primordialmente, não organicamente. Portanto, oscilam, dispersam-se, abrandam-se ou se tornam violentos, intolerantes, briguentos, ao sabor dos acasos e das contingências. Para que se entenda melhor, tenho um conceito socrático de cultura: creio que seja um pensar bem, qualquer coisa que se pense, e portanto, executar bem, qualquer coisa que se faça (GRAMSCI apud SHCLESENER, 2002, p.42).
}

Observaremos o vínculo entre a organização política dos trabalhadores de Turim e a necessidade de uma nova concepção de cultura, relacionada a partir das necessidades do projeto revolucionário da época. Levamos em consideração que a Itália passou por um processo tardio para transformar-se em Estado capitalista:

Cujos traços distintivos mostram as dificuldades de formação de uma burguesia nacionalmente unida e combativa no contexto das relações internacionais e a constituição de grupos burgueses com expressão regional que, para desencadear o processo de unificação, precisaram apoiar-se na força organizativa de um Estado já instituído, o Piemonte (SCHLESENER, 2002, p.17).

Devemos nos lembrar, no entanto, que na Itália não teve a formação de um partido jacobino e nenhuma orientação no Partido de Ação para tornar-se um partido dirigente. A revolução na Itália se apresentava contra os tratados antigos, contra a ordem internacional e contra a Áustria - que mantinha o país e ocupava parte do território italiano, além de controlar o restante. Segundo Gramsci, a questão do Risorgimento foi transformada em uma questão 
patriótica e econômica que devem ser analisadas ao levar em consideração a fraqueza da burguesia italiana diferente das burguesias europeias. Para o autor, as diferenças da Itália e dos outros países europeus devem ser vistas a partir do desenvolvimento histórico e das relações internacionais das nações.

A relação entre a cidade e o campo é um problema antigo na Itália e demonstrava certo sentimento de ódio para com os camponeses nas cidades urbanas. Já se manifestava de modo embrionário a relação entre Norte e Sul como uma relação entre a grande cidade e o campo e, consequentemente, surgiu um problema de nacionalidade. Esse processo foi permeado por consequências políticas e culturais, por um lado, os camponeses deslocados do processo de modernização e, do outro lado, uma maior modernização e inserção no capitalismo, mesmo que tardio. Isto acentuou as diferenças e distâncias culturais, políticas e econômicas.

A questão histórica sobre as transformações econômico-sociais da Itália nos interessa para compreendermos o que Gramsci compreende por cultura, em primeiro momento, em sentido amplo; posteriormente quando é relacionado com a questão organizativa do proletariado. A cultura, então, compreendida como uma reflexão crítica que está interrelacionada com a organização da classe trabalhadora nos Conselhos de Fábrica, que teve como órgão midiático de expressão cultural e político a revista semanal L'Ordine Nuovo: rassegna settimanale di cultura socialista. O jornal L'Ordine Nuovo foi fundado em $1^{\circ}$ de maio de 1919, na cidade operária turinesa, pelos jovens universitários Angelo Tasca, Umberto Terracini, Palmiro Togliatti.

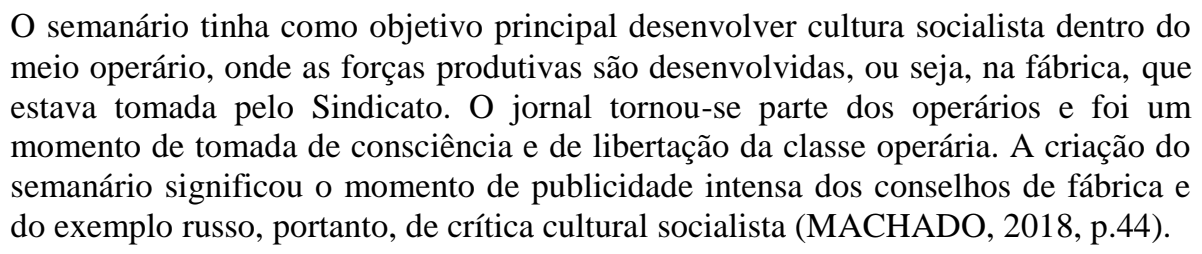

A reflexão de Gramsci acerca de cultura e política passa pelo debate sobre a questão da ideologia e de como o Estado liberal e a Igreja colaboram para criar o imaginário social do povo, um modo de pensar, de agir e de viver que é capaz de se expressar como um processo coordenado capaz de mobilizar multidões.

A questão de fundo colocada por Gramsci nos anos anteriores ao Cárcere, com textos possíveis de serem encontrados na organização de Carlos Nelson Coutinho, Os escritos político, volume 1 e volume 2 , retrata a Itália como um país de capitalismo tardio, permeado por desigualdades culturais, sociais, políticas e econômicas. Além do Estado burguês, que colabora junto às suas instituições para a conservação desse panorama, alguns partidos e a 
linha reformista e além do liberalismo que "se alimenta do apego do senso comum à ordem estabelecida" (SCHLESENER, 2002, p.31). As diversas ações políticas que não têm como plano de ação a reforma intelectual e moral acabam por conservar a ordem de maneira prática ideológica e por meio do senso comum.

Mesmo com o momento de convulsão política - também devido à influência da revolução na Rússia -- e de organização do proletariado no Partido Socialista Italiano, a necessidade da ação prática exigia dos trabalhadores um questionamento aprofundado sobre as questões do cotidiano, além de crítica a orientação partidária. Era necessário que o proletariado turinês compreendesse a importância da organização operária para a ação política. Dessa forma, a teoria marxiana é fundamental para que o homem e o seu processo de trabalho não sejam dissociados, ao contrário, ambos devem se identificar como um ato histórico de forma que compreendam sua função ao longo da história e de seus processos revolucionários.

Devemos nos recordar que neste período, nos anos de juventude e de militância de Gramsci no Partido Socialista, o autor fazia inúmeras críticas à linha reformista e positivista do Partido, da qual sempre discordou radicalmente - e que pode ser encontrada em seus textos jornalísticos da juventude:

É possível observar o historicismo e a forma que o autor se coloca contrário à posições naturalistas e mecanicistas, de modo que o debate é realizado em torno da questão teórico-política. O jovem sardo já se posicionava contrário aos partidos sectários e positivistas, além das correntes particularistas e eleitoreiras (MACHADO, 2018, p.23).

A partir das leituras de Gentile e Croce ${ }^{2}$, Gramsci absorve uma leitura das obras de Marx, e politicamente há certa influência de Sorel, Rosa Luxemburg e também da Revolução Russa. O autor acaba por se aproximar da corrente massimalista de Amadeo Bordiga e prossegue nas críticas sobre as incrustações positivistas no Partido, além de elaborar uma reflexão a partir da necessidade de uma ação política que solucionasse o problema da questão italiana e que estimulasse a consciência crítica dos trabalhadores.

O problema italiano passava pela questão católica, também relacionada com a educação e com a ideologia e cultura do povo, que exercia grande poder político e ideológico na mentalidade do país.

Deixar que a consciência das crianças seja manipulada pelos padres, seja seduzida pela vaidade, pelo clericalismo, pelo lacrimoso espírito cristão, é permitir que os meninos sejam submetidos a uma violência. Por uma falsa concepção de tranquilidade doméstica, muitos deixam que isso aconteça. Tranquilidade doméstica assume aqui o significado de covardia. Covardia do homem que renuncia à sua

\footnotetext{
${ }^{2}$ Rompe com Croce após o autor apoiar a guerra.
} 
tarefa de educador (...) Aos filhos dos proletários deve ser deixada a liberdade de poder escolher, em idade mais madura, o caminho que melhor lhes agrade; não se deve criar nenhuma hipoteca sobre seu caráter, sobre seu futuro (GRAMSCI, 2004a, p. 99).

Além da Igreja e sua representatividade, Gramsci realiza uma crítica ao PSI no artigo Homens ou Máquinas, publicado no jornal Avanti! em 24 de dezembro de 1916, na coluna La scuola e $i$ socialisti.

Uma escola que não hipoteque o futuro da criança e não constrinja sua vontade, sua inteligência, sua consciência em formação a mover-se por um caminho cuja meta seja prefixada. Uma escola de liberdade e de livre iniciativa, não uma escola de escravidão e de orientação mecânica (GRAMSCI, 2004a, p. 75).

As críticas realizadas por Gramsci estão relacionadas com a falta de um programa político e educacional do Partido para as escolas italianas. $\mathrm{O}$ autor se debruça em críticas à escola na Itália, que era uma escola para os filhos dos patrões e que não educava os filhos do proletariado. Segundo o autor, a escola italiana pertencia à burguesia que, diferente do proletário para tornar-se homem de cultura precisava ser autodidata já que necessita vender sua força de trabalho e não tinha tempo, condições estruturais e energia para estudar. O debate sobre a escola e a cultura foi importante para Gramsci no que cerne a reflexão de seu projeto de socialismo e novo Estado.

Portanto, a cultura se tornou um privilégio e não deveria ser. A escola, por sua vez, também tornou-se um privilégio. Segundo Gramsci, todos os jovens deveriam ser iguais perante a cultura. Neste sentido, o PSI tem o papel de incluir os filhos dos proletários como homens de cultura e esses jovens precisam de uma escola desinteressada ${ }^{3}$, com a possibilidade de tornarem-se homens e adquirirem critérios para a formação do caráter (MACHADO, 2018, p.27).

O debate sobre a educação é de grande importância na obra de Gramsci - lembramos que não é o foco do autor, que esteve voltado para a política e economia, mas quando a educação é relacionada com a questão cultural e com a organização política, torna-se essencial para compreender os acontecimentos dos dois anos vermelhos na Itália (1919-1920) --, pois é uma das contribuições políticas quando se discute o homem integral e a formação humana. Como demonstrado acima, Gramsci reflete sobre uma educação que desenvolva a individualidade do trabalhador e que lhe abra portas para pensar dentro da coletividade, de modo que a disciplina faça parte da vida do operário, que a cultura seja adquirida de maneira crítica e reflexiva e que o estudante tenha liberdade para pensar e agir.

O debate sobre a categoria de folclore em Gramsci é necessário para compreendermos a relação que possui com o campesinato. Para o autor, estudar o folclore

\footnotetext{
${ }^{3}$ É possível notar a atualidade de Gramsci neste artigo ao falar das escolas técnicas italianas, caso pensarmos a realidade da educação brasileira.
} 
implica compreender uma concepção do mundo e da vida que muitas vezes está implícita nos estratos de tempo e de espaço da sociedade, e em oposição com as concepções de mundo localizadas na parte culta.

Concepção do mundo não só não elaborada e assistemática - já que o povo (isto é, o conjunto das classes subalternas e instrumentais de toda forma de sociedade que existiu até agora) não pode, por definição, ter concepções elaboradas, sistemáticas e politicamente organizadas e centralizadas em seu (ainda que contraditório) desenvolvimento-, como também múltiplo (GRAMSCI, 2001b: 134).

Para Schlesener (2002, p.30), o senso comum, habituado a entender a realidade a partir de oposições dualistas, sem compreender e enfrentar as contradições, temeroso ante as incertezas do que uma mudança radical poderia trazer, sofre o "poder taumatúrgico" dessa palavra, cuja força contribui para garantir a conservação das instituições políticas. O senso comum apega-se, então, à ordem instituída, ao presente e às garantias que ele oferece, embora mínimas, renunciando a arriscar-se para não sentir a insegurança ante o desconhecido.

Dessa forma, o folclore é compreendido como um reflexo e representação das condições culturais de um povo. Há uma relação entre folclore e senso comum que significa um nexo. Cada camada social possui seu senso comum e as correntes filosóficas também deixam camadas de senso comum que se transformam de modo contínuo. Portanto, para Gramsci, a cultura é como um saber que é produzido na ação e no pensamento que cria e que transforma a organização dos trabalhadores e camponeses.

\section{CONSElHos de FÁbrica e CUlTuRA: PARA A CONSTRUÇÃo de} UM NOVO ESTADO

É na observação do cotidiano que podemos encontrar esse nexo que é capaz de um novo costume, uma nova ética e uma nova possibilidade de transformação social. Para Gramsci, a cultura é uma categoria base e fundamental do socialismo, pois integra o conceito de liberdade de pensamento e propõem que seja verificado pelo conceito de organização, no sentido de organizar a cultura e organização da vida política. Compreende o vínculo e a relação entre cultura e socialismo, cultura e educação, cultura e organização política, cultura e revolução socialista, pois a organização compreendida como o modo de ser e de agir que se traduz no modo de pensar.

Todos esses significados se articulam no conceito de organização, enquanto um modo de ser e agir que se traduz num modo de pensar. A partir de sua organização política, os trabalhadores explicitam sua concepção de mundo e solidificam suas lutas. A organização expressa uma forma efetiva de união e de solidariedade entre os homens, diferente das relações vividas na sociedade capitalista, onde os indivíduos não se unem, apenas se agregam. Assim, a partir da ação política, noções como 
individualidade, união, associação, liberdade, disciplina, passam a ter um novo sentido (SCHELESENER, 2002, p.49).

Para Gramsci, a organização substitui a noção de individualismo. É um tipo de liberdade para todos e uma garantia das liberdades individuais. A organização política está relacionada com a crítica que o autor realiza aos sindicalistas e aos socialistas que defendem uma concepção mecanicista do socialismo.

A questão central do vínculo entre a organização política, a cultura e a revolução é compreender a análise de Gramsci a partir da necessidade de criação de novos órgãos que conectem os trabalhadores por um entusiasmo e que crie um hábito intelectual. Nesse sentido, que tenha a necessidade em criar novos órgãos de formação cultural que superem o campo economista. A construção do socialismo também está relacionada com a disciplina constante e metódica, a disciplina que compreende a vontade concreta em construir a vida.

A esta disciplina, que se identifica com a coerção, contrapõe-se a disciplina
socialista, autônoma e espontânea, fruto não da obediência cega a leis que não se
compreende, mas da vontade concreta em construir uma vida conforme
determinados objetivos (SCHELESENER, 2002, p.52).

Nos escritos gramscianos a questão da autodisciplina está relacionada com a organização do modo de produzir. A autodisciplina, para o intelectual sardo, é um tipo de disciplina diferente da que é imposta pelo patrão nos padrões tayloristas, fordistas ou toyotistas. A disciplina referida é aquela que o próprio operário irá adquirir direto do trabalho. O trabalho volta à condição que Marx se refere em $O$ Capital, como uma condição sóciometabólica do homem, pois é o trabalho com finalidades produtivas e não pela extração de mais-valia relativa e enriquecimento das elites, de maneira que o proletariado tem a capacidade de desenvolver a consciência enquanto trabalha e de se organizar nas instituições.

O socialismo é organização da política e da economia, mas também é o saber da vontade obtida por meio da atividade da cultura. Esse é o trabalho que as instituições deveriam criar, mas nem o Partido Socialista ou a Confederazione Generale del Lavovo (CGL) foram capazes de realizar com disciplina revolucionária. De tal modo, Turim tornou-se o local onde a revolução seria possível.

Os operários organizaram os primeiros conselhos de fábrica no verão de 1919, Antonio Gramsci e Angelo Tasca, futuros fundadores do Partido Comunista, iniciaram a publicação da revista L'Ordine Nuovo, que exercia certa influência na ala mais à esquerda metalomecânico, uma das mais fortes federações pertencentes à Confederazione Generale del Lavoro (CGDL) (GALASTRI, 2015, p.52).

Estas ocupações desenvolveram um caráter revolucionário que acometera grande impacto à opinião pública. Como esperado, o patronato preocupou-se e buscou desenvolver forças repressivas para controlar este processo. O semanário L'Ordine Nuovo tornou-se parte 
dos operários e pode ser visto como uma fase de desenvolvimento de consciência e de libertação da classe operária. A criação do semanário significou o momento de publicidade intensa dos Conselhos de Fábrica e do exemplo russo, portanto, de crítica cultural socialista.

\begin{abstract}
Pois bem: o único sentimento que nos unia, naquelas nossas reuniões, era suscitado pela vaga paixão de uma vaga cultura proletária; queríamos fazer, fazer e fazer; sentíamos angustiados, sem uma orientação, mergulhados na ardente vida daqueles meses que se sucederam ao armístico, quando parecia imediato o cataclisma da sociedade italiana (GRAMSCI, 2004a, p.401) ${ }^{4}$.
\end{abstract}

No artigo de junho de 1919, Democracia Operária, Gramsci compreende questões importantes para o desenvolvimento do Estado socialista, com base na experiência russa. Segundo o autor, as Comissões Internas foram os órgãos da democracia operária que limitam o poder do Estado capitalista e desenvolvem-se para ser um órgão do poder proletário: os Conselhos. As Comissões Internas são o primeiro elo que leva à ditadura do proletariado que tem como bons exemplos a Rússia, a Hungria e a Alemanha. No caso italiano, seria necessário também que os bairros possuíssem comitês para abranger toda a classe trabalhadora e que se ampliassem e se disciplinassem, dialeticamente, junto ao PSI.

A partir das organizações desenvolvidas e massificadas, organizaram-se para o exercício do poder. Gramsci relembra a necessidade cotidiana de debates que deveriam ser realizados pela ação comunista, discussões que modificassem as consciências dos trabalhadores para que assimilassem a revolução russa. "Sim, existe na Itália, em Turim, um germe de governo operário, de soviete: é a comissão interna" (GRAMSCI, 2004a, p.402).

O autor interpreta a experiência dos Conselhos como um momento decisivo e de grande importância para a classe operária. O Conselho de Fábrica, segundo Gramsci, "é o embrião do Novo Estado.”. Seria, naquele período, a única organização possível de adquirir consciência por meio da relação dialética de auto educação, de educação recíproca entre os operários do Conselho e do Partido.

\begin{abstract}
O conselho de fábrica é o modelo do Estado proletário. Todos os problemas inerentes à organização do Estado proletário são inerentes à organização do conselho. Num e noutro, desaparece o conceito de cidadão, substituído pelo conceito de companheiro: a colaboração para produzir bem e de modo útil desenvolve a solidariedade, multiplica os vínculos de afeto e de fraternidade. Cada um é indispensável, cada um está em seu lugar, todos têm uma função e um posto (GRAMSCI, 2004a, p. 288).
\end{abstract}

Os Conselhos seriam necessários para organizar a economia e a política juntas, de modo dialético e diferente da forma que o sindicato realizava - já que ele não era baseado na

\footnotetext{
${ }^{4}$ O artigo citado é de agosto de 1920, quando Gramsci rememora os anos de criação e polêmica com Angelo Tasca que segundo Gramsci, não participou da experiência e foi hostil à realização dos Conselhos. Ver Gramsci, 2004a, p. 405.
} 
vida fabril, mas na vida salarial que agia como um mercado profissional-. O Conselho de Fábrica foi uma instituição de caráter público, já o Partido e o Sindicato, segundo Gramsci, foram associações de caráter privado e contratualistas.

No Conselho, o operário tornou-se parte da fábrica como produtor. Entretanto, no partido e no sindicato o operário ingressava de modo voluntário e assinava um compromisso, de modo contratual, que poderia ser rompido quando conveniente e desejado. "O exemplo de Turim era para nós emblemático; e, por isso, num de nossos artigos, Turim foi apresentada como a forja da revolução comunista italiana" (GRAMSCI, 2004a, p. 406).

\footnotetext{
Os conselhos de fábrica têm sua lei em si mesmos, não podem e não devem aceitar legislação dos organismos sindicais, já que têm a finalidade imediata de renovar fundamentalmente tais organismos. (...) o movimento dos conselhos de fábrica quer que a representação operária seja uma emanação direta das massas (...) (GRAMSCI, 2004a, p.410).
}

A função dos Conselhos foi de realizar a democracia operária, de se tornar um órgão político do proletariado italiano, capaz de organizar a produção, a política e a cultura, e que tenha como ação a democracia direta. Esse trabalho deveria ser realizado nos órgãos criados pelos trabalhadores. A questão da cultura está intrínseca a isso, pois a formação cultural foi uma questão basilar para um movimento capaz de enfrentar os problemas econômicos e políticos da sociedade italiana. Gramsci também desenvolve a questão da importância do Partido em transformar força econômica em força política, com a intransigência agindo como um princípio democrático. Dessa forma, os Conselhos agiriam como um primeiro momento; a função do Partido revolucionário seria a de transformar e organizar as forças sociais e substituir a ordem burguesa, superando os limites do corporativismo e do reformismo - o que ocorreria apenas no processe revolucionário.

Os Conselhos de Fábrica foram a tradução dos Sovietes de Petrogrado que inauguraram a revolução russa, em 1905. Gramsci participou ativamente da tentativa revolucionária turinense e elaborou debates no periódico L'Ordine Nuovo sobre a relação dos Conselhos com o Sindicato e com o Partido Socialista. Demonstrado por Gramsci nos escritos juvenis, o PSI não foi capaz de organizar as classes subalternas para fazer a revolução e foi incapaz de dirigir o processo revolucionário, colocando-se longe do debate e do apoio ao movimento dos Conselhos de Fábrica no período conhecido como Biennio Rosso (19191920).

Mesmo sem o apoio necessário do Partido e do Sindicato, o proletariado organizado nos conselhos de 1919-1920, demonstraram a capacidade e o poder da classe trabalhadora para a elaboração de uma nova forma social, política e econômica. Os conselhos traduziram 
diretamente a possibilidade de o trabalhador gerir, por meio da autogestão e da auto educação, o processo fabril do modo de produção de mercadorias.

Devemos lembrar que para o autor, a conquista do Estado socialista está relacionada com a cultura e com o internacionalismo, já que o marxismo de Gramsci compreende a cultura como uma organização crítica do saber e das necessidades históricas da sociedade, realizado por meio da práxis revolucionária e nos detalhes do cotidiano que levam o proletariado a identificar e se desvincular das amarras da sociedade capitalista.

\section{CONSIDERAÇÕES FINAIS}

Gramsci teoriza em torno do marxismo e da revolução socialista, o que permite acrescentar a importância do intelectual na segunda fase da Refundação Comunista. O militante sardo nos deixou muitos textos que colaboram com o desenvolvimento da teoria política do socialismo, do Estado, da política e da hegemonia. A importância da filosofia da práxis, elaborada e definida desde os anos anteriores, contempla uma análise das situações e das correlações de força que fundam os Estados. Desta forma, abre também espaço para uma teoria das relações internacionais sistêmicas que contemplam o papel de cada hegemonia e o uso diversificado, por meio das relações de força, dos determinados cenários geográficos e históricos. Pois, a hegemonia nunca é igual, é mutável e varia de nação para nação, colônia para colônia, de modo que o militarismo é exercido e regulado distintamente.

Por fim, a construção da teoria revolucionária não é possível sem o confronto entre as classes e a organização político-cultural. A classe revolucionária não consegue conquistar e exercer a hegemonia quando privada de legitimidade, de maturidade, de organização e de cultura, que são as bases para o rompimento da exploração do trabalho e para a construção de um novo Estado.

O materialismo histórico permite a classe trabalhadora compreender o tempo em que se encontra, além de proporcionar uma base histórica que é fundamental para as mudanças cotidianas e mais radicais. A teoria política gramsciana desenvolveu-se no curso da luta de classes como forma explicativa e revolucionária para tais mudanças e, ainda hoje, é possível de ser utilizada. Todavia, a classe trabalhadora atual, devido nosso período de decadência ideológica, mostra-se incapaz de compreender suas raízes históricas, junto às raízes dos problemas e conflitos econômicos-político, culturais e sociais.

Portanto, o nosso tempo mostra a necessidade de resgatar experiências - que este trabalho buscou analisar - para que as classes subalternas conheçam suas histórias e possam 
entender o presente e saber de sua capacidade de transformação do real. O materialismo histórico não deve permanecer na exclusão de interpretar as relações sociais e as relações de produção geradas pelo capitalismo, pois é capaz de ser uma nova forma de conceber a vida e de transformar as relações humanas.

\section{REFERÊNCIAS BIBLIOGRÁFICAS}

GALASTRI, L. Gramsci, Marxismo e Revisionismo. Campinas: Autores Associados, 2015.

GRAMSCI, Antonio. Escritos Políticos, vol.1 (1911-1921). (org.). e tradução de Carlos Nelson Coutinho. Rio de Janeiro: Civilização Brasileira, 2004a.

\section{Quaderni del Carcere. A}

cura di Valentino Gerratana. Torino: Einaudi, 1977.

LIGUORI, Guido. VOZA, Pasquale. (org.). Dicionário Gramsciano (19261937). São Paulo: Boitempo, 2017.

BARATTA, G. Cultura In LIGUORI, Guido. VOZA, Pasquale. (org.).
Dicionário Gramsciano (1926-1937). São Paulo: Boitempo, 2017.

MACHADO, Marília. Conselhos de Fábrica e Partido no Jovem Gramsci: A relação entre os Conselhos de Fábrica, o Partido e o Sindicato (1911-1921). 01. ed. Novas Edições Acadêmicas, 2018. v. 01. $115 \mathrm{p}$.

, Gramsci e a aliança operáriocamponesa. REVISTA ENSAIOS, v. 11, p. 67-78, 2017.

SCHLESENER, A. Revolução e cultura em Gramsci. Curitiba: UFPR, 2002.

\section{THE IMPORTANCE OF CRITICAL CULTURE IN THE CONSTRUCTION OF A NEW STATE}

Marília Gabriella Borges Machado

How to cite this article: MACHADO, Marília Gabriella Borges. A importância da cultura crítica na construção de um novo Estado. Revista de Ciências do Estado. Belo Horizonte: v. 5, n. 1, e13164. ISSN: 2525-8036.

Abstract: It is a theoretical work that undertakes a historical approach. The central objective of this study is to follow the theoretical / practical apprehension of Antonio Gramsci regarding the experience of the Factory Councils as the foundation of a new democracy, of a new State from the link between culture and socialism. Culture is defined as the sphere, thought, structure of activities and construction of consciousness carried out by intellectual layers, that is, by the masses who exercise organizational functions in production and cultural mode. Therefore, this work intends to carry out an analysis of the function of the culture related to the experience of the Factory Councils in Turin (1919-1920), so that the organizational question becomes evident in the concept of culture. The sources used are the 
texts of Antonio Gramsci and important authors who discuss the Gramscian theory, in order to get an understanding of the political and theoretical scenario that Gramsci was in.

Key-worlds: culture; Gramsci; socialism. 